06

\title{
Пороги инициирования и динамические характеристики взрыва для тонких образцов композитов ТЭН-АІ при лазерном воздействии
}

\author{
() Б.П. Адуев, Д.Р. Нурмухаметов, Н.В. Нелюбина, И.Ю. Лисков \\ Федеральный исследовательский центр угля и углехимии СО РАН, \\ 650000 Кемерово, Россия \\ e-mail: lesinko-iuxm@yandex.ru
}

Поступило в Редакцию 9 августа 2018 г.

В окончательной редакции 9 августа 2018 г.

Принято к публикации 21 декабря 2018 г.

Измерены пороги $H_{c r}$ взрывчатого разложения тонких $(h=1 \mathrm{~mm})$ образцов композитов ТЭН-Al с плотностями в диапазоне $\rho=0.9-1.7 \mathrm{~g} / \mathrm{cm}^{3}$ и вариации концентраций включений алюминия в диапазоне 0.025-1.0 mass.\% при воздействии импульсов излучения неодимового лазера $(\lambda=1064 \mathrm{~nm}, 14 \mathrm{~ns})$. Для каждой $\rho$ установлены концентрации включений $n_{o p t}$, при которых порог взрывчатого разложения Hcr минимален. Определены скорости ударных волн (УВ) в воздухе в зависимости от плотности $\rho$ образцов и времена начала взрывчатого разложения в зависимости от концентрации включений. Определена амплитуда (в относительных единицах) и временной сдвиг максимума давления УВ на пьезодетектор в зависимости от плотности образцов. Сделан вывод, что при высоких значениях $\rho$ взрыв происходит по ударно-волновому механизму. По мере уменьшения $\rho$ образцов увеличивается полнота взрыва, при этом наиболее вероятным механизмом при малых $\rho$ является взрывное горение. Эффективность взрывного разложения выше для образцов с меньшими плотностями.

DOI: $10.21883 /$ JTF.2019.06.47640.308-18

\section{Введение}

Исследование взрывчатых веществ (BВ) при воздействии лазерных импульсов началось во второй половине 60-х годов прошлого века [1-3]. Из бризантных ВВ (БВВ) наиболее исследован тетранитрат пентаэритрита (ТЭН). Ряд результатов изложен в монографии [4]. Механизм инициирования, базирующийся на образовании горячих точек при лазерном воздействии, удобно изучать, если в матрицу прозрачного ВВ включить светопоглощающие добавки. Первые работы такого плана показали возможность значительного снижения порога инициирования [5,6]. Это открыло практическую перспективу разработки материалов, обладающих высокой чувствительностью БВВ к лазерному излучению для применения их в качестве рабочего тела светодетонаторов штатных ВВ [7]. В этом направлении следует также отметить работы $[8,9]$. Наиболее полно исследование порогов лазерного инициирования композитов на основе ТЭН с включениями металлов и углеродных материалов отражено в наших работах, например [10-15] (всего более 20 работ).

Результаты исследования порогов взрыва при лазерном воздействии для образцов ТЭН без включений в диапазоне плотностей $\rho=0.5-1.4 \mathrm{~g} / \mathrm{cm}^{3}$ приведены в [4]. Однако до настоящего времени не проведено исследование взрывчатых характеристик композитов ВВ в зависимости от плотности образцов $\rho$.

Кроме порогов инициирования не менее важными характеристиками являются скорости ударных волн, возникающих при взрыве в воздухе, их давление на объекты и значение этих параметров при различных плотностях образцов.

Вышеперечисленным вопросам посвящена настоящая работа, особенностью которой является использование тонких образцов $(h=1 \mathrm{~mm})$ композитов ТЭН-Al.

\section{1. Образцы и методика}

В качестве матрицы для изготовления композитных материалов использовался порошок ТЭН с узким гранулометрическим распределением с размером зерен $1-2 \mu \mathrm{m}$. В качестве включений использовался порошок $\mathrm{Al}$ с размерами частиц в максимуме распределения $100 \mathrm{~nm}$. Частицы алюминия покрыты оболочкой из окиси алюминия (27 mass.\%), прозрачной для лазерного излучения. Методика подготовки исходных порошков ТЭН-Al и изготовления образцов методом прессования подробно описана в работе [10].

$a$

$b$

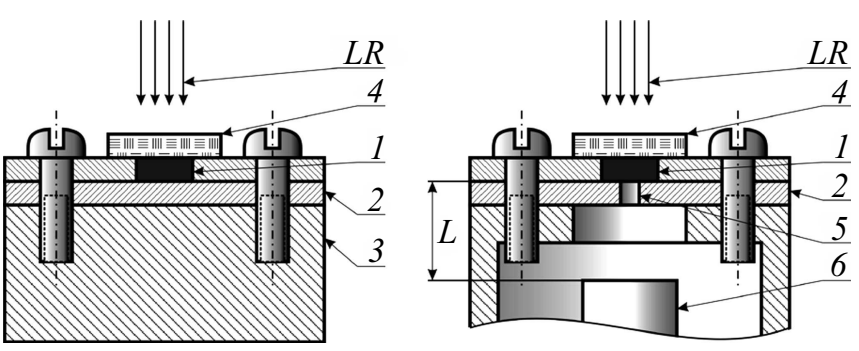

Рис. 1. Функциональные схемы экспериментальных ячеек (обозначения в тексте). 


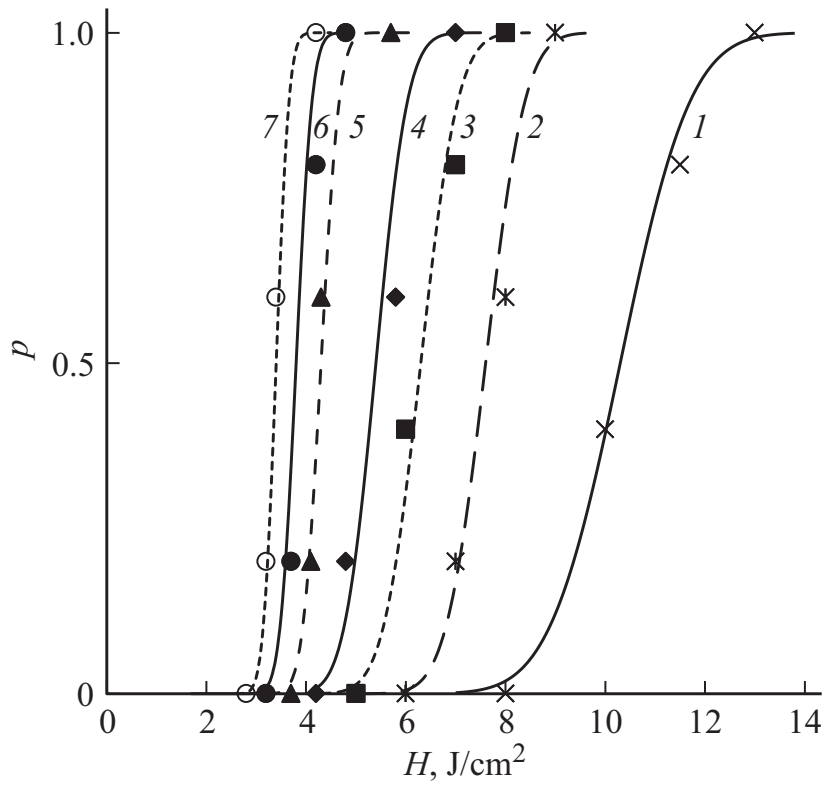

Рис. 2. Зависимости вероятности взрыва $(\rho)$ от плотности энергии лазерного излучения $(H)$ для образцов ТЭН плотностью $0.9 \mathrm{~g} / \mathrm{cm}^{3}$ с включениями наночастиц алюминия различной концентрации: $1-1.0 ; 2-0.025 ; 3-0.1 ; 4-0.2$; $5-0.75 ; 6-0.5 ; 7-0.6$ mass.\% соответственно.

Образцы композитов прессовались в медной пластине (держателе образца), в центре которой имелось отверстие диаметром $3 \mathrm{~mm}$, толщиной $1 \mathrm{~mm}$. Кроме того, использовались пластины толщиной 2 и $2.8 \mathrm{~mm}$ для изучения влияния массы образцов на динамические характеристики.

Методика изготовления образцов с различной плотностью $\rho$ заключалась в следующем:

$$
\rho=4 m h / \pi d^{2},
$$

где $m$ - масса образца, $d$ - диаметр образца, $h$ толщина образца; $d$ и $h$ - величины постоянные. Изменение $\rho$ производилось за счет изменения $m$.

В отверстие $d$ перед прессованием засыпались различные навески смеси порошка ТЭН с Al: $m=6.3$; $7.7 ; 9.2 ; 10.6$ и $12.0 \mathrm{mg}$. После прессования получали соответственно образцы с плотностями $\rho=0.9 ; 1.1 ; 1.3$; $1.5 ; 1.7 \mathrm{~g} / \mathrm{cm}^{3}$. Проверка плотности $\rho$ готовых образцов производилась следующим образом. Медная пластина взвешивалась на аналитических весах без образца и после прессования с образцом. По разности масс определялась масса $m$ образца с точностью $0.01 \mathrm{~g}$. Толщина пластины $h$ измерялась микрометром с точностью $0.01 \mathrm{~mm}$, диаметр $d$ измерялся с использованием микроскопа, точность измерения составляла $0.01 \mathrm{~mm}$. Далее вычислялась плотность $\rho$ по формуле (1).

В качестве источника инициирования взрыва использовано излучение первой гармоники $\mathrm{YAG}: \mathrm{Nd}^{3+}$-лазера $\left(\lambda=1.064 \mu \mathrm{m}, \tau_{i}=14 \mathrm{~ns}\right)$, работающего в режиме модулированной добротности. Излучение лазера (ЛИ) фо- кусировалось на образец в пятно диаметром $2.5 \mathrm{~mm}$. Плотность энергии излучения, выводимая на образец, регулировалась с помощью калиброванных стеклянных светофильтров.

Схема эксперимента представлена на рис. 1. При пороговых измерениях (рис. $1, a$ ) пластина с образцом 1 помещалась на дюралевую пластину-свидетель 2, которая располагалась на массивном основании 3. Со стороны излучения образец накрывался стеклянной пластиной, толщиной $1 \mathrm{~mm} \mathrm{4,} \mathrm{которая} \mathrm{блокировала} \mathrm{газодинамиче-}$ скую разгрузку образца.

Схема измерения скорости и давления ударных волн изображена на рис. $1, b$. Отличия от рис. $1, a$ следующие: дюралевая пластина-свидетель заменялась на медную 2,c отверстием 5 (диаметром $1 \mathrm{~mm}$ ), через которое выходят продукты взрыва, и возникает ударная волна (УВ) в воздухе. УВ действует на пьезодетектор 6, сигнал которого регистрируется осциллографом LeCroy WJ332A. При измерении скорости и давления УВ, плотность энергии в лазерном импульсе была максимальна и равнялась $40 \mathrm{~J} / \mathrm{cm}^{2}$. Выбор плотности энергии обусловлен необходимостью достижения вероятности взрыва > 99\%.

\section{2. Эксперимент и обсуждение}

В разд. 1 исследовались пороги взрывчатого разложения композитов ТЭН-Al в диапазоне плотностей образцов $\rho=0.9-1.7 \mathrm{~g} / \mathrm{cm}^{3}$ при вариации концентрации включений $\mathrm{Al} n=0.025-1$ mass. $\%$.

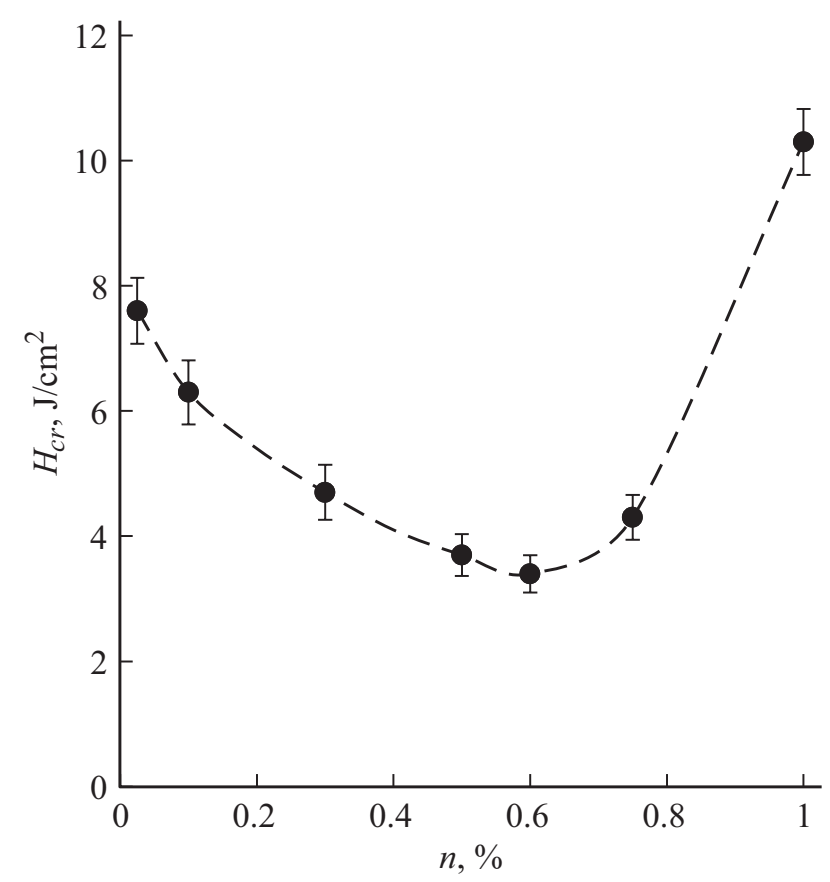

Рис. 3. Зависимость критической энергии инициирования $\left(H_{c r}\right)$ ТЭН от концентрации включений алюминия $(n)$ для образцов плотностью $0.9 \mathrm{~g} / \mathrm{cm}^{3}$. 
Пороговые и динамические характеристики взрывчатого разложения композитов ТЭН-Al

\begin{tabular}{c|c|c|c|c|c}
\hline$\rho, \mathrm{g} / \mathrm{cm}^{3}$ & 0.9 & 1.1 & 1.3 & 1.5 & 1.7 \\
\hline$H_{c r}^{\min }, J / \mathrm{cm}^{2}$ & 3.3 & 3.2 & 2.1 & 1.0 & 0.7 \\
$n_{\text {opt }}, \mathrm{mass} \%$ & 0.6 & 0.5 & 0.4 & 0.3 & 0.2 \\
$V_{i}, \mathrm{~km} / \mathrm{s}$ & 4.8 & 4.5 & 3.8 & 3.2 & 2.4 \\
$\rho_{z i}$, ns & 40 & 80 & 160 & 280 & 450 \\
$P_{\max }$, r.u. & 46 & 40 & 30 & 17 & 8 \\
$t_{\max }, \mu \mathrm{s}$ & 4.3 & 4.6 & 5.3 & 5.7 & 6.1 \\
$J_{\max }$, r.u. & 4.7 & 4.0 & 3.3 & 2.4 & 1.5 \\
$m_{i}$, r.u. & 0.9 & 0.89 & 0.86 & 0.75 & 0.63
\end{tabular}

Примечание: $\rho-$ плотность образца, $H_{c r}^{\min }-$ минимальный порог взрывчатого разложения образцов при оптимальной концентрации $n_{o p t}, V-$ скорость УВ в воздухе, $\tau_{z i}-$ время задержки взрыва, $P_{\max }-$ максимальное значение давления (в отн.ед.) УВ в воздухе, $t_{\max }-$ время достижения $P_{\max }, J_{\max }-$ максимальное значение удельного импульса (в отн.ед.) в момент времени $t_{\max }, m_{i}-$ масса частиц среды (в отн.ед.), увлекаемых УВ.

Для этого измерялись вероятности взрыва от плотности энергии лазера (кривые частости). Для получения кривых частости взрыва при фиксированной плотности энергии последовательно облучались 10 образцов с определенной плотностью $\rho_{i}$ и концентрацией включений $n_{i}$. Варьируя плотность энергии, получали зависимость вероятности взрыва от плотности энергии лазерного излучения, падающей на образец. Эксперимент повторялся при заданной плотности образцов $\rho_{i}$ в диапазоне концентрации включений 0.025-1 mass.\%. Далее эксперименты повторялись при различных плотностях образцов в диапазоне $\rho=0.9-1.7 \mathrm{~g} / \mathrm{cm}^{3}$ при вариации концентраций включений $n$.

Для примера на рис. 2 приведено семейство кривых частости для образцов с плотностью $\rho=0.9 \mathrm{~g} / \mathrm{cm}^{3}$. Сплошные линии проведены через экспериментальные точки с использованием интегральной функции ошибок при помощи метода максимального правдоподобия [16]:

$$
P(H)=\frac{1}{2}\left\{1+\operatorname{erf}\left[\frac{H-H_{c r}}{\sqrt{2} \Delta H_{c r}}\right]\right\} .
$$

Из обработки кривых частости типа рис. 2 для всех исследованных образцов находили значения критической плотности энергии $H_{c r}$, определяемой как плотность энергии, соответствующая 50\% вероятности взрыва, и среднеквадратичное отклонение $\Delta H_{c r}$. Для примера результаты обработки кривых частости образцов с плотностью $\rho=0.9 \mathrm{~g} / \mathrm{cm}^{3}$ представлены на рис. 3 .

Кривые зависимости $H_{c r}(n)$ при других плотностях образцов носят такой же немонотонный характер.

Объяснение немонотонного хода зависимостей $H_{c r}(n)$ дано в работах $[11,13]$. Минимальные критические плотности энергии $H_{c r}^{\min }$ и соответствующие им концентрации включений, которые далее будем называть оптимальными $n_{o p t}$, для образцов с различной плотностью пред- ставлены в таблице. Из таблицы видно, что увеличение плотности образцов ведет к уменьшению $H_{c r}^{\min }$ и $n_{\text {opt }}$.

В разд. 2 использовались такие же образцы композитных материалов, как и в разд. 1. Имеющаяся экспериментальная методика позволяет проводить измерения скорости и давления УВ в воздухе с помощью пьезодетектора (см. разд. 1).

Продукты взрыва вылетали через отверстие 5 в медной пластине 2 (рис. $1, b$ ), от чего в воздухе возникала головная УВ [17], опережающая продукты взрыва. Пролетая расстояние $L$, УВ воздействовала на пьезодетектор 6 (рис. $1, b)$. Сигнал пьезодетектора регистрировался при помощи осциллографа. Чтобы точнее зарегистрировать начало процесса увеличения давления на пьезодетектор, чувствительность осциллографа увеличивалась до значения $0.005 \mathrm{~V} / \mathrm{div}$ для регистрации начала фронта возрастания давления. В результате получали осциллограммы типа, представленной на рис. 4.

В экспериментах рабочая поверхность пьезодетектора устанавливалась на различных расстояниях $(L)$ от образца 1 (рис. $1, b)$ и измерялся временной интервал между лазерным воздействием на образец и моментом появления регистрируемого сигнала $t_{s}$. Величина $L$ варьировала в диапазоне 2-6 $\mathrm{mm}$.

Эксперименты проводились с образцами для всех использованных плотностей с оптимальной концентрацией включений $n_{\text {opt }}$ для каждой плотности. Результаты представлены на рис. 5.

Из рис. 5 видно, что все зависимости времени появления сигнала от расстояния $L$ между тыльной поверхностью образца и пьезодетектором имеют линейный характер, т.е. эксперимент проводили в ближней зоне, когда ослабление скорости УВ в воздухе еще не заметно.

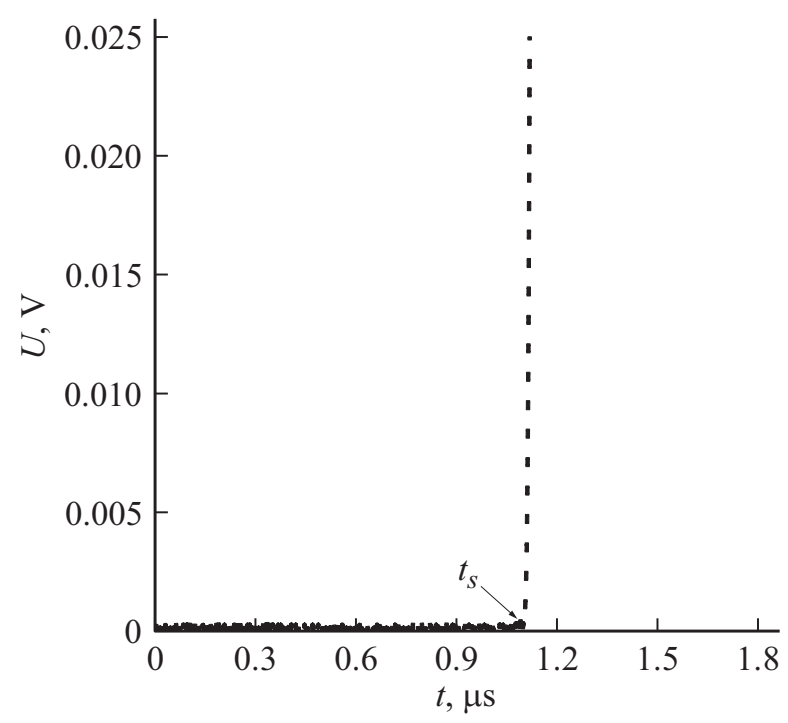

Рис. 4. Типичная осциллограмма пьезодетектора (чувствительность $0.005 \mathrm{~V} / \mathrm{div})$. Образец - ТЭН с включениями 0.5 mass.\% частиц алюминия, плотность $1.1 \mathrm{~g} / \mathrm{cm}^{3}$. Расстояние от образца до пьезодетектора $3 \mathrm{~mm}$. $\tau_{s}$ - момент появления регистрируемого сигнала. 


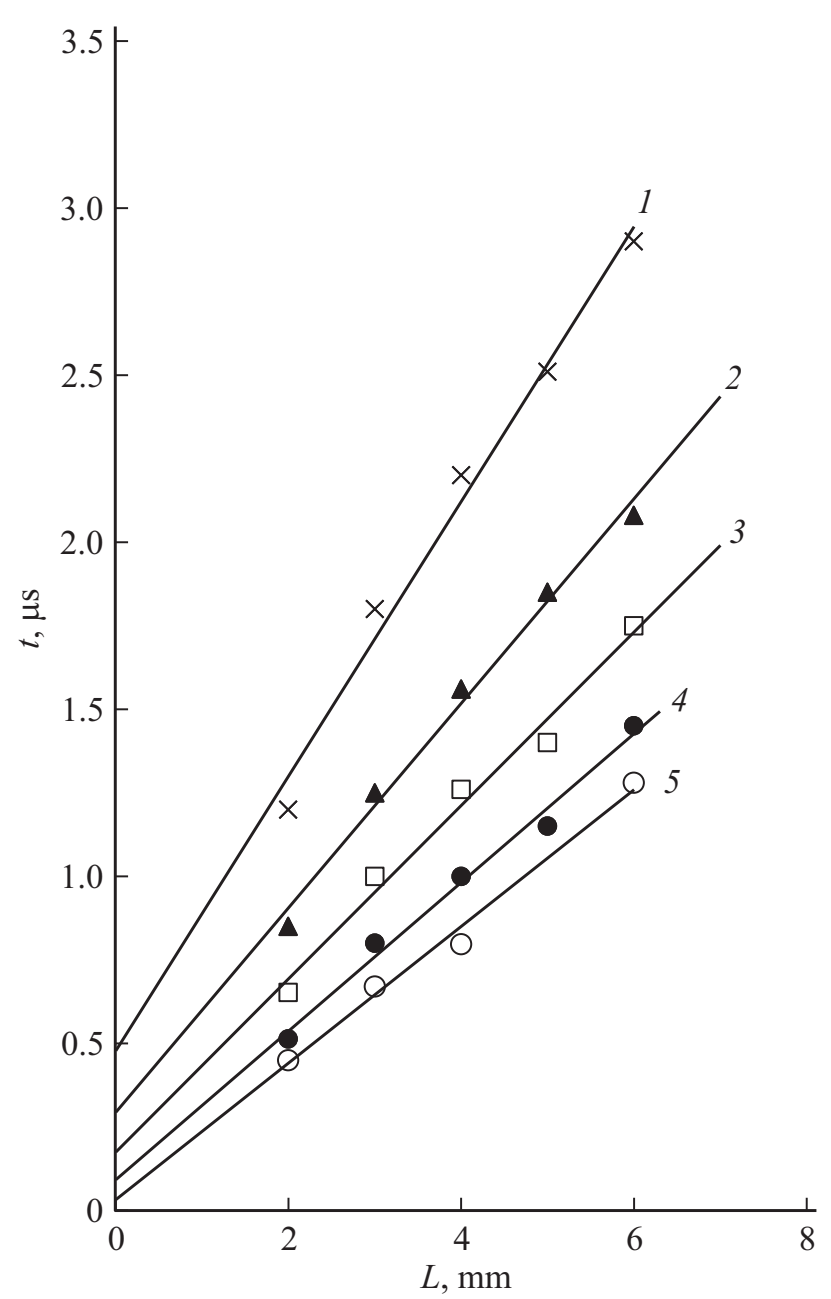

Рис. 5. Зависимость времени появления сигнала $\tau_{s}$ пьезодетектора от расстояния до образца $L$. Образцы: ТЭН с включениями частиц алюминия с $n_{\text {opt }}$ при разных плотностях $\rho .1-0.2 \%, \rho=1.7 \mathrm{~g} / \mathrm{cm}^{3} ; 2-0.3 \%, \rho=1.5 \mathrm{~g} / \mathrm{cm}^{3}$; $3-0.4 \%, \rho=1.3 \mathrm{~g} / \mathrm{cm}^{3} ; 4-0.5 \%, \rho=1.1 \mathrm{~g} / \mathrm{cm}^{3} ; 5-0.6 \%$, $\rho=0.9 \mathrm{~g} / \mathrm{cm}^{3}$.

Следовательно, по наклону прямых на рис. 5 можно определить скорости УВ для плотности образца $\rho_{i}$. Уравнение прямых на рис. 5 можно представить в виде

$$
t_{s}=\tau_{z i}+\frac{1}{V_{i}} \cdot L_{i}
$$

где $t_{s}$ - время распространения УВ от тыльной поверхности образца до пьезодетектора при соответствующем $L_{i} ; V_{i}$ - скорость УВ при соответствующих $\rho_{i} ; L_{i}-$ расстояние от тыльной поверхности образца до пьезодетектора; $\tau_{z i}$ - момент времени пересечения прямых с осью ординат, который соответствует времени вылета продуктов на тыльной стороне образца, т.е. времени задержки взрыва. Результаты для $V_{i}$ и $\tau_{z i}$, полученные с использованием рис. 5 и уравнения (3), представлены в таблице.

Из таблицы видно, что с ростом плотности образцов $\rho_{i}$ уменьшается скорость УВ, а время задержки взрыва $\tau_{z i}$ растет с уменьшением концентрации включений $n_{\text {opt }}$.

С помощью пьезодетектора можно измерить только $d P / d \tau$, что следует из сущности самого явления пьезоэффекта. Поэтому для получения $P(\tau)$ необходимо интегрировать экспериментальные осциллограммы.

На рис. 6 для примера представлена экспериментальная осциллограмма, измеренная с помощью пье-

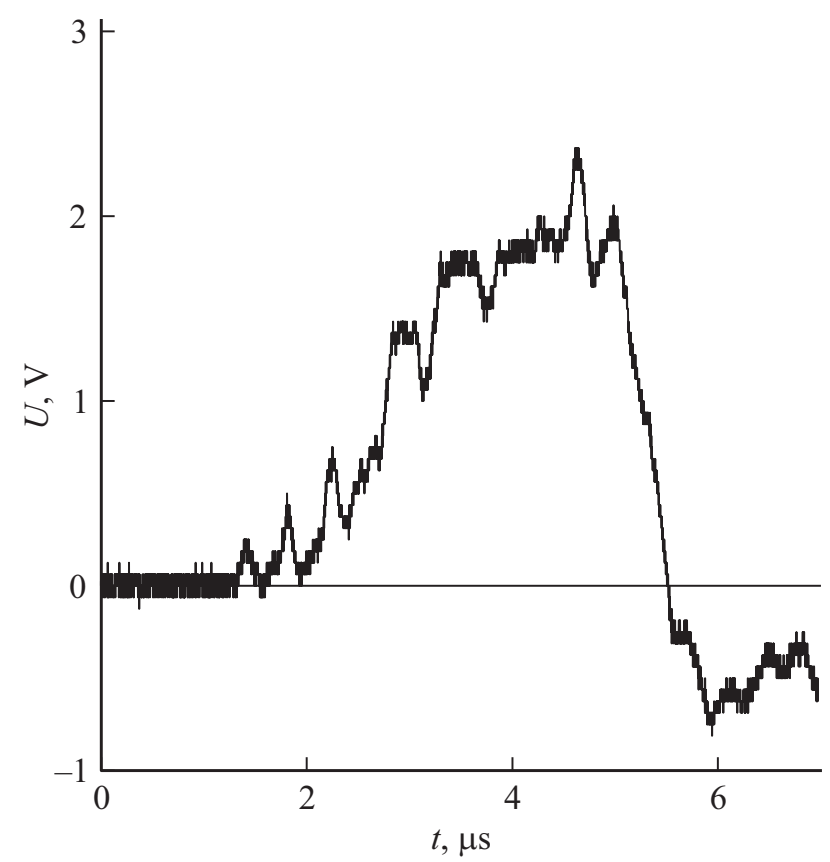

Рис. 6. Типичная осциллограмма пьезодетектора (чувствительность 2 V/div). Образец - ТЭН с включениями 0.5 mass.\% частиц алюминия, плотность $1.1 \mathrm{~g} / \mathrm{cm}^{3}$, толщина образца $1 \mathrm{~mm}$.

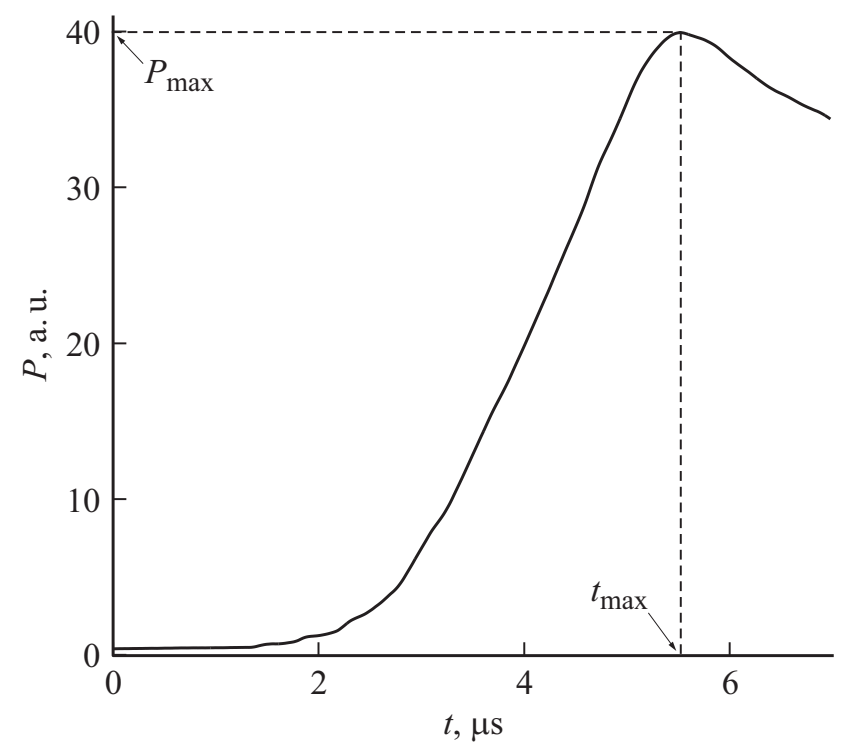

Рис. 7. Зависимость давления ударной волны от времени в относительных единицах, полученных в результате интегрирования осциллограммы рис. 6. 


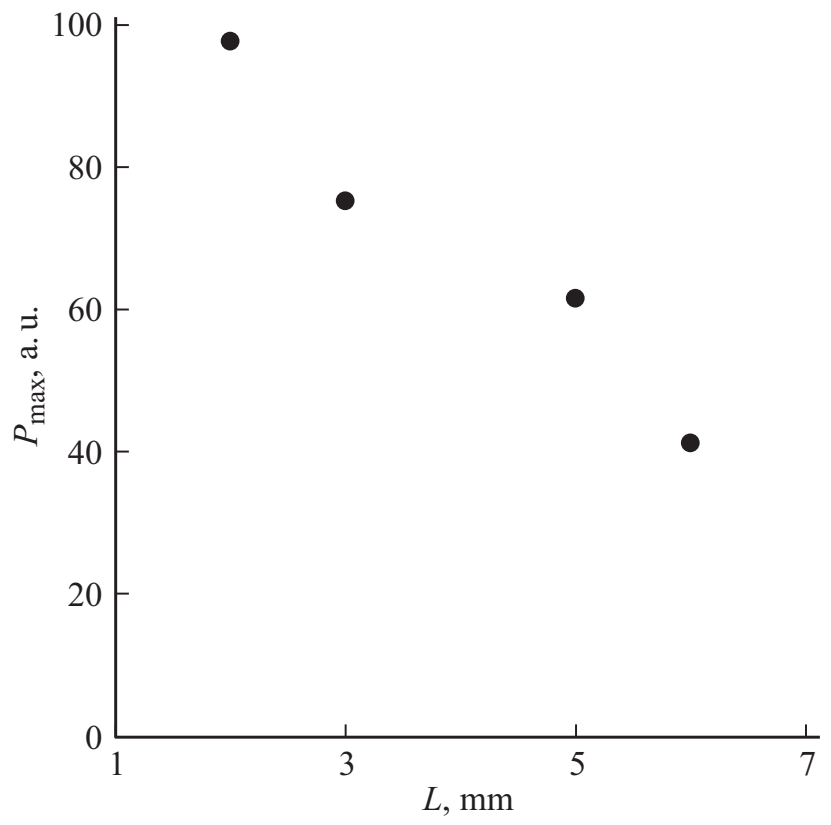

Рис. 8. Зависимость максимального давления в относительных единицах от расстояния $L$ между тыльной стороной образца и пьезодетектором.

зодетектора, в координатах $U(\tau)$, где $U-$ сигнал, регистрируемый осциллографом. Поскольку калибровка пьезодетектора на измерение абсолютных значений давлений $P(t)$ весьма проблематична, то $P(t)$ можно получить в относительных единицах:

$$
P(t)=\int_{t_{s}}^{t} U(t) d t .
$$

Результат интегрирования осциллограммы рис. 6 представлен на рис. 7.

Аналогичные операции были проделаны для всех образцов с различными $\rho$. Максимальные значения $P_{\max }$ и времени достижения $T_{\max }$ для образцов с разными $\rho$ при фиксированном расстоянии $(L=6 \mathrm{~mm})$ между тыльной поверхностью образца и пьезодетектором представлены в таблице.

Из таблицы следует, что с увеличением плотности $\rho$ образцов уменышается максимальное давление УВ при взрыве образца и увеличивается время $t_{\max }$ достижения $P_{\text {max }}$.

Измерение давления в зависимости от расстояния $L$ между тыльной поверхностью образца и пьезодетектором представлены на рис. 8 .

Из рисунка следует, что с увеличением $L$ уменьшается $P_{\max }$, несмотря на то, что скорость УВ остается постоянной.

Была проведена проверка влияния массы образца на $P_{\max }$. Для этого использовались образцы с различной толщиной (см. разд. 1). Из геометрии образца видно, что $h \sim m$. Соответствующая зависимость представлена на рис. 9. Из рисунка следует, что $P_{\max } \sim \sqrt[3]{m}$.

Таким образом, из результатов, представленных в таблице, следует, что в тонких образцах композитов TЭН-Al нормальная детонация не осуществляется, так как с ростом $\rho$ образцов уменьшается $V$ и $P$ в УВ. Для нормальной детонации должна наблюдаться обратная ситуация [17]. По классификации, приведенной в [17], ес-

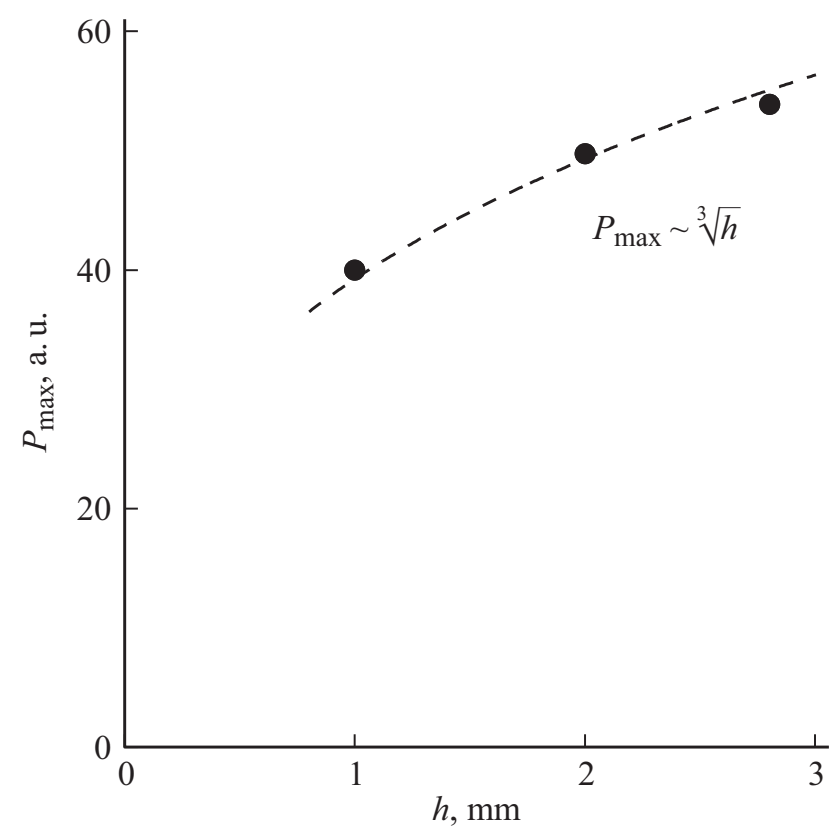

Рис. 9. Зависимость максимального давления в относительных единицах от толщины образца.

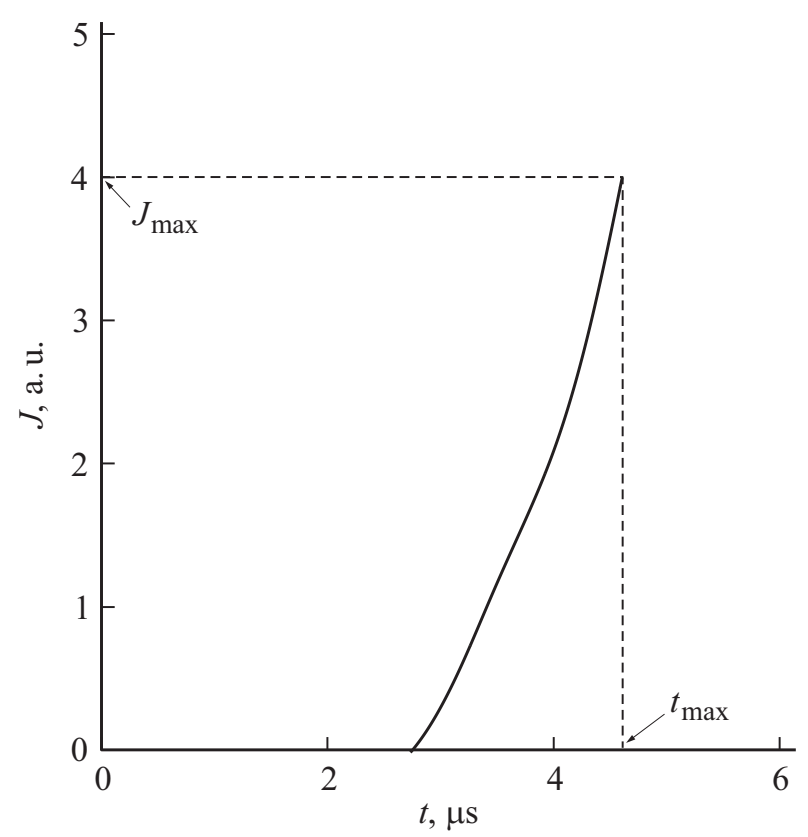

Рис. 10. Зависимость удельного импульса ударной волны от времени в относительных единицах, полученных в результате интегрирования осциллограммы рис. 7. 
ли ориентироваться на диапазон измеренных скоростей, наблюдаемые эффекты можно отнести к низкоскоростной детонации.

Рассмотрим ситуацию подробнее. Удельный импульс $J$, который переносит УВ в воздухе, при $L=\mathrm{const}$ можно представить в виде

$$
J_{i}(t)=\int_{0}^{1} P_{i}(t) d t .
$$

Индекс $i$ относится к образцам с одинаковой плотностью. Удельный импульс можно получить интегрированием кривых типа, представленных на рис. 7. Результат интегрирования для кривой рис. 7 представлен на рис. 10.

Аналогичная операция проделана для всех образцов с различными $\rho$. Значения $J_{\max }$ в моменты времени $t_{\max }$ при достижении максимального давления $P_{\max }$ представлены в таблице. Для наглядности значения $J_{\max }$, представленных в таблице, нормированы на значения при плотностях образцов $1.7 \mathrm{~g} / \mathrm{cm}^{3}$.

Для $J$ можно также записать выражение при определенном $\rho_{i}$ :

$$
J_{i}=m_{i} V_{i},
$$

где $m_{i}$ - масса частиц среды, увлекаемых УВ.

Отсюда

$$
m_{i}=\frac{J_{i}}{V_{i}}
$$

Результаты для $m_{i}$ для каждой $\rho_{i}$ представлены в таблице. Таким образом, совокупность результатов свидетельствует, что увеличение плотности образцов $\rho$ приводит к уменьшению $m_{i}, \rho_{i}, V_{i}, H_{c r}^{\min }, n_{\text {opt }}$.

Анализ совокупности результатов позволяет объяснить закономерности лазерного инициирования тонких образцов композитов ТЭН-Аl. Для плотных образцов $\left(\rho=1.7 \mathrm{~g} / \mathrm{cm}^{3}\right)$ наблюдаемый низкий порог инициирования можно объяснить хорошим контактом частиц матрицы с включениями Al. Как показано в [14], при лазерном облучении образцов с $\rho=1.7 \mathrm{~g} / \mathrm{cm}^{3}$ с пороговой плотностью энергии показатель поглощения излучения $k \geq 200 \mathrm{~cm}^{-1}$, и, следовательно, инициирование химической реакции происходит преимушественно вблизи поверхности образца до глубины $d=k^{-1} \leq 50 \mu \mathrm{m}$. В этом слое образуются „горячие точки“, представляющие собой нагретые частицы Al и окружающую их оболочку матрицы, которая уже за время лазерного импульса прогревается до расстояния

$$
l=\sqrt{\chi \cdot \tau_{i}}
$$

где $\chi$ - температуропроводность ТЭН, $\tau_{i}$ - длительность лазерного импульса.

Оценка показала, что $l \approx 40 \mathrm{~nm}$, а нагрев оболочки, окружающей частицы $\mathrm{Al}$, достаточен для достижения температуры вспышки [12]. При этом в облученной области выделяется газ, увеличивается давление, образуется и распространяется в необлученную часть образца УВ, что приводит к взрыву. Однако эффективность этого процесса невысока. Поскольку толщина образца мала, химическая реакция не успевает развиться в полной мере и поддерживать УВ для достижения ей детонационной скорости $D$. Поэтому, по-видимому, значительная часть образца разбрасывается, т.е. полнота взрыва не высокая, о чем свидетельствуют минимальные значения $V$, $P_{\max }, J_{\max }, m_{i}$.

При уменьшении плотности образцов порог инициирования возрастает из-за ухудшения контакта частиц $\mathrm{Al}$ с матрицей. Однако после инициирования, из-за увеличения пористости и теплопроводности образцов [17], условия распространения тепла из „горячих точек“ и инициирования химической реакции в необлученной части образца улучшаются [17]. В этом случае инициирование реакции в необлученной части образца может опережать ударную волну по механизму взрывного горения, предложенному в [18]. По мере уменьшения плотности образцов этот механизм дает увеличивающийся вклад. При этом чем ниже $\rho$, тем лучше динамические характеристики взрыва: растут $V, P_{\max }, i_{\max }, m_{i}$, уменьшается $\tau_{z i}$ (см. таблицу). Следовательно, что с уменьшением $\rho$ растет полнота взрыва образца, т.е. увеличивается эффективность взрывчатого разложения.

Отметим, что наблюдаемые особенности характерны для тонких образцов. При увеличении толщины образцов до характерной величины (дистанции пробега УВ до детонации) скорость УВ в образце возрастает до детонационной $D$ и будут наблюдаться хорошо известные закономерности характеристик взрыва при нормальной детонации [17].

\section{Заключение}

Таким образом, в тонких образцах композита ТЭН-Al наблюдаются следующие закономерности.

1. С ростом плотности композитов уменьшаются пороги лазерного инициирования.

2. С ростом концентрации включений алюминия в образце уменьшается задержка взрыва.

3. Скорости ударных волн в воздухе постоянны на расстоянии до $6 \mathrm{~mm}$ от места взрыва и уменьшаются с возрастанием плотности образцов.

4. С возрастанием плотности образцов уменьшается давление ударных волн, образующихся при взрыве образцов.

5. Для плотных $\left(\sim 1.7 \mathrm{~g} / \mathrm{cm}^{3}\right)$ образцов взрыв происходит по ударно-волновому механизму. Полнота взрыва невысокая.

6. По мере уменьшения плотности образцов включается механизм взрывного горения, при этом эффективность взрывного разложения (полнота взрыва) увеличивается. 


\section{Финансирование работы}

Исследование выполнено в рамках программы „Фундаментальные научные исследования (ГП 14)“ по теме V.49.1.5., рег. ном. АААA-A17-117041910150-2.

\section{Список литературы}

[1] Бриш А.А., Галеев И.А., Зайщев Б.Н., Сбитнев Е.А., Татаринщев Л.В. // ФГВ. 1966. Т. 2. № 3. С. 132-133.

[2] Галеев И.А., Зайщев Б.Н. // ФГВ. 1969. Т. 5. № 3. С. 447.

[3] Бриш А.А., Галеев И.А., Зайцев Б.Н., Сбитнев Е.А., Татаринцев Л.В. // ФГВ. 1969. Т. 5. № 4. С. 475-480.

[4] Быстрое инициирование ВВ. Особые режимы детонации / Сб. науч. статей под ред. В.И. Таржанова. Снежинск.: Издво РФЯЦ-ВНИИТФ, 1998. $168 \mathrm{c.}$

[5] Александров В.Е., Долголаптев А.В., Иоффе В.Б. и др. // ФГВ. 1983. Т. 19. № 4. С. 17-20.

[6] Иоффе В.Б., Долголаптев А.В., Александров В.Е., Образцов А.П. // ФГВ. 1985. Т. 21. № 3. С. 51-55.

[7] Krupa T.J. // Optics and Photonics News. 2000. Vol. 11. N 6. P. 16.

[8] Александров Е.А., Вознюк А.Г., Ципилев В.П. // ФГВ. 1989. T. 26. № 1. C. 3-9.

[9] Таржсанов В.И., Сдобнов В.И., Зинченко А.Д., Погребов А.И. // ФГВ. 2017. Т. 53. № 2. С. 118-125.

[10] Адуев Б.П., Белокуров Г.М., Нурмухаметов Д.Р., Нелюбина Н.В. // ФГВ. 2012. Т. 48. № 3. С. 127-132.

[11] Адуев Б.П., Нурмухаметов Д.Р., Звеков А.А., Никитин А.П., Каленский А.В. // ФГВ. 2016. Т. 52. 6. C. $108-115$.

[12] Адуев Б.П., Нурмухаметов Д.Р., Белокуров Г.м., Нелюбина Н.В. // Опт. и спектр. 2018. Т. 124. № 3. С. 404-409.

[13] Адуев Б.П., Нурмухаметов Д.Р., Звеков А.А., Никитин А.П., Ковалев Р.Ю. // Химическая физика. 2016. Т. 35. № 7. C. $38-43$.

[14] Адуев Б.П., Нурмухаметов Д.Р., Фурега Р.И., Лисков И.Ю. // Химическая физика. 2014. Т. 33. № 12. C. $29-32$.

[15] Адуев Б.П., Нурмухаметов Д.Р., Нелюбина Н.В., Ковалев Р.Ю., Никитин А.П., Заостровский А.Н., Исмагилов 3.P. // ФГВ. 2016. Т. 52. № 5. С. 108-115.

[16] Ван дер Варден Б.Л. Математическая статистика. М.: ИИЛ, 1960.

[17] Физика взрыва / Под ред. Л.П. Орленко. М.: Физматлит, T. 1. 2004.

[18] Апин А.Я. // ДАН СССР. 1945. Т. 50. С. 285-288. 